[2] Stannus, O. Circulating levels of IL-6 and TNF-alpha are associated with knee radiographic osteoarthritis and knee cartilage loss in older adults/O. Stannus, G. Jones, F. Cicuttini et al. Osteoarthr. Cartil. 2010:18(11):1441-1447.

[3] Louati K. et al. Association between diabetes mellitus and osteoarthritis: systematic literature review and meta-analysis. RMD open. 2015;1(1).

Disclosure of Interest: None declared

DOI: 10.1136/annrheumdis-2017-eular.5940

\section{AB0797 LONG TERM PROSPECTIVE MULTICENTER RANDOMIZED PLACEBO-CONTROLLED STUDY OF HYALURONIC ACID IN SMALL JOINTS OSTEOARTHRITIS (SJOA)}

E. Tsvetkova ${ }^{1}$, L. Denisov ${ }^{1}$, E. Panasyuk ${ }^{1}$, E. Nasonov ${ }^{2} .{ }^{1}$ Clinical Research laboratory; ${ }^{2}$ Scientific Leader, V.A. Nasonova Research Institute of Rheumatology, Moscow, Russia, Moscow, Russian Federation

Objectives: Assessment of the efficacy, tolerability and period of aftereffect of the single administration into 1st carpometacarpal and 1st metatarsophalangeal OA joints of $1.0 \mathrm{ml}$ (20mg) of hyaluronic acid (Durolane) as compared with placebo. Methods: The study included 120 pts with OA of small hand joints or feet, pain intensity $>40 \mathrm{~mm}$ by VAS and consisted of two phases: "blind" phase up to 24 weeks, period of assessment of long term efficacy results -48 weeks. The efficacy was assessed by $40 \%$ pain subsiding, index AUSCAN (for the hand), dose of NSAID, total effect assessment.

Results: Both groups were comparable by basic clinical criteria, $40 \%$ pain subsiding by VAS $(\mathrm{mm})$ was noted in experimental group to 24 th week in $79.7 \%$, in the placebo group $-30 \%$ (chi-square: $p<10^{-5}$ ), relation of chances (OR) equal to 9.1 (3.9-21.1). Dispersion analysis of pain, stiffness and function of AUSCAN index revealed reliable differences between Durolane and placebo. Statistically significant difference $(p<0.0001)$ according to assessment of general condition by the doctor and patient were found out in experimental group from the 4th week and were stable till 48th week. Adverse effects related to the therapy were not found. NSAID dose was decreased in $45.7 \%$ in experimental group and in $30 \%$ in placebo group.

Conclusions: efficacy and considerable duration of aftereffect of single administration of Durolane SJ (small joints) as compared with placebo was demonstrated in 24 and 48 weeks.

Disclosure of Interest: None declared

DOI: 10.1136/annrheumdis-2017-eular.5740

\section{AB0798 AMTOLMETIN GUACIL-EFFECTIVE AND GOOD SAFE NONSTEROIDAL ANTI-INFLAMMATORY DRUG IN KNEE OSTEOARTHRITIS PATIENTS WITH DYSPEPSIA}

E. Tsvetkova ${ }^{1}$, L. Denisov ${ }^{1}$, E. Nasonov ${ }^{2}$ on behalf of AGATA group. ${ }^{1}$ Clinical Research laboratory; ${ }^{2}$ Scientific Leader, V.A.Nasonova Research Institute of Rheumatology, Moscow, Russia, Moscow, Russian Federation

Objectives: To investigate the efficacy and tolerability of amtolmetin guacil (AMG; Niselat ${ }^{\circledR}$, Dr. Reddy's Laboratories Ltd, India) versus previous therapy with nonsteroidal anti-inflammatory drugs (NSAIDs) in patients with knee osteoarthritis $(\mathrm{OA})$ and signs of dyspepsia.

Methods: The open-label observational study included 220 patients aged 30-65 years who suffered from knee OA and intense pain during NSAID intake and had symptoms of dyspepsia in the absence of contraindications to the use of AMG. Among the comorbidities that generally occurred in $68 \%$ of the patients, there was a preponderance of hypertension $(42 \%)$, lower extremity varicose veins $(6.4 \%)$, and diabetes mellitus $(6 \%)$.

Treatment efficacy was evaluated using three domains of the Western Ontario and McMaster Universities Osteoarthritis Index (WOMAC), by also taking into account pain intensity and general health assessment on the visual analogue scale. A Severity of Dyspepsia Assessment (SODA) scale was used to rate dyspepsia.

Results: AMG had a marked analgesic effect confirmed by $40 \%$ or more pain reduction thatoccurred in $72.5 \%$ of the patients. The high analgesic effect of AMG was confirmed by a statistically significant $(p<0.001)$ reduction in the WOMAC index (pain and stiffness) and by an increase in functional activity. Therewas a significant decrease in painless and painful signs of dyspepsia, as well as positive changes in the measures "overall assessment of dyspepsia severity" $(p<0.001)$ and "satisfaction with treatment". Overall assessment ofAMG tolerability was only positive: excellent $(33 \%)$, good $(56 \%)$, and satisfactory $(11 \%)$. There were no seriousadverse events (AE). AE were graded as moderate and mild in 8 and $82 \%$ of cases, respectively. $A E$ were recordedin $7.7 \%$ of the patients.

AMG had a marked analgesic effect confirmed by $40 \%$ or more pain reduction that occurred in $72.5 \%$ of the patients. The high analgesic effect of AMG was confirmed by a statistically significant $(p<0.001)$ reduction in the WOMAC index (pain and stiffness) and by an increase in functional activity. There was a significant decrease in painless and painful signs of dyspepsia, as well as positive changes in the measures "overall assessment of dyspepsia severity" $(p<0.001)$ and "satisfaction with treatment". Overall assessment of AMG tolerability was only positive: excellent $(33 \%)$, good $(56 \%)$, and satisfactory $(11 \%)$. There were no serious adverse events (AE). AE were graded as moderate and mild in 8 and $82 \%$ of cases, respectively. AE were recorded in $7.7 \%$ of the patients.
Conclusions: The findings suggest that AMG offers good prospects for knee OA treatment.

Acknowledgements: Otteva A.N., Dubikov A.I., Yakupova S.P., Ivanova O.N., Korshunov N.I., Vaisberg A.R., Abyshev R.A., Tartynov A.V.

Disclosure of Interest: None declared

DOI: 10.1136/annrheumdis-2017-eular.5253

\section{AB0799 DECREASED RATIO OF TIMP1/MMP-9 IS ASSOCIATED WITH HIGHER PAIN SENSITIVITY IN A SUBSET OF OSTEOARTHRITIC PATIENTS WITH LOW MECHANISTIC TARGET OF RAPAMICIN GENE EXPRESSION IN THE PERIPHERAL BLOOD}

E.V. Tchetina ${ }^{1}$, G.A. Markova ${ }^{1}$, E.A. Taskina ${ }^{2}$, N.G. Kashevarova ${ }^{2}$, E.P. Sharapova ${ }^{2}$, L.I. Alekseeva ${ }^{2} .{ }^{1}$ Immunology \& Molecular Biology; ${ }^{2}$ Osteoarthritis, Nasonova Research Institute of Rheumatology, Moscow, Russian Federation

Background: Progression of osteoarthritis (OA) produces loss of articular cartilage that may culminate in pain, loss of joint function, and disability. Osteoarthritic changes in articular cartilage are associated with progressive proteolytic degradation of the extracellular matrix due to excessive expression of metalloproteinases (MMPs) over their tissue inhibitors (TIMPs). At the same time, decrease in TIMP concentration versus MMP has been previously associated with an increase in pain sensitivity.

Objectives: Here we hypothesized that imbalance in TIMP1 and MMP-9 gene and protein expressions in the peripheral blood might contribute to pain perception in OA patients.

Methods: We examined whole blood of 65 OA outpatients and 27 healthy subjects. Clinical testing comprised physical examination, radiographic and WOMAC scoring, and ultrasonography. Total RNA isolated from the whole blood was used for gene expression examination of mTOR, mechanistic target of rapamycin, a major regulator of cell growth and proliferation, metalloproteinase MMP-9, and tissue inhibitor of metalloproteinase, TIMP1 using quantitative Realtime RT-PCR. p70-S6K (mTOR read-out), MMP-9, and TIMP1 protein levels were quantified by ELISA.

Results: 23 OA outpatients exhibited significant downregulation of mTOR gene expression (subset "Low mTOR") while other 42 OA outpatients have demonstrated upregulation of mTOR gene expression (subset "High mTOR") in the peripheral blood compared to healthy controls. Although both OA outpatient subsets had comparable radiographic severity according to Kellgren-Lawrence grading, similar age, disease duration, and body mass index, "Low mTOR" patients experienced significantly higher pain at joint function versus "High mTOR" subset. This was associated with a significant upregulation of MMP-9 gene expression in "Low mTOR" patients versus healthy subjects while TIMP1 expression remained equal to controls. In a "High mTOR" subset, both gene expressions were significantly upregulated. p70-S6K and TIMP1 protein concentrations measured in the peripheral blood mononuclear cells were significantly lower in "Low mTOR" patients versus that in "High mTOR" while MMP-9 protein expression was significantly higher compared to healthy subjects in both examined OA subsets. Conclusions: Our results show that TIMP1 and MMP-9 gene expressions measured in the peripheral blood might be associated with pain sensitivity in OA outpatients while low level of TIMP1/MMP-9 ratio indicates increased pain perception.

Disclosure of Interest: None declared DOI: 10.1136/annrheumdis-2017-eular.2254

\section{AB0800 KNEE OSTEOARTHRITIS PATIENTS' USE OF AND COMPLIANCE TO AN ORTHOTIC INTERVENTIONS}

E. Mauricio, M. Sliepen, D. Rosenbaum. Universitätsklinikum Münster, Münster, Germany

Background: Knee osteoarthritis (KOA) is the most common form of arthritis with an estimated lifetime prevalence of $44.7 \%$ (1). The use of orthotic devices (knee braces, insoles, wedged shoes) is a generally accepted conservative therapy for KOA patients (2). However, it is suggested that their effectiveness is detrimentally affected by poor patient compliance due to discomfort while wearing these devices (3).

Objectives: The aim of this study is to objectively establish the compliance to an orthotic intervention using a thermal sensor (TS) and comparing it to patients self-reported wear time.

Methods: Ten medial KOA patients (mean \pm SD age $57.6 \pm 13.4$ years, BMI $27.3 \pm 3.2 \mathrm{~kg} / \mathrm{m}^{2}$ ), clinically diagnosed according to the ACR Guidelines, were recruited for this study. A small, light-weight TS with the size of an average lithium battery $\left(0.5^{\circ} \mathrm{C}\right.$ resolution) was placed in a newly developed ankle-foot-orthosis (AFO) that patients were asked to wear as often as possible during a period of six weeks. The TS measured the temperature every 5 minutes for 4 weeks. Patients rated the comfort of the orthosis during the first visit using a scale from 1 to 5 (1 being the most comfortable).

Additionally, the patients reported during these six weeks how many hours per day they had worn the orthosis and rated which amount of pain they felt each day (from $0=$ no pain to $10=$ most painful). To determine the patients' compliance, the AFO wear time, derived from the TS, was compared to the wear time per day recorded in the patients' diaries. The threshold to differentiate the wear 